\title{
ANÁLISE DA GESTÃO DE LICENCIAMENTO DE PATENTES: ESTUDO MULTICASOS DE INSTITUIÇÕES FEDERAIS DE ENSINO SUPERIOR
}

\section{Rodrigo Milano Lucena}

Mestre em Administração pela Universidade Federal de Mato Grosso do Sul - UFMT

Professor do Centro Universitário Anhanguera

milano.rodrigo@hotmail.com (Brasil)

\section{Renato Luiz Sproesser}

Doutor em Génie des Systèmes Industriels pelo Institut National Polytechnique de Lorraine - INPL Professor da Universidade Federal de Mato Grosso do Sul - UFMT dlrs@nin.ufms.be (Brasil)

\section{RESUMO}

A busca da inovação pelas empresas torna-se necessária devido ao aumento da competitividade e as universidades têm papel importante quando são parceiras na geração de tecnologia e inovação. Sendo assim, a proposta desse estudo consistiu em discutir o modo como as universidades de ponta brasileiras fazem a gestão das patentes geradas a fim de transferir a sociedade. As análises foram baseadas em pesquisas feitas nas universidades da amostra e para ilustrar esse gerenciamento foram utilizadas as ferramentas $5 \mathrm{~W} 1 \mathrm{H}$ e fluxogramas para melhor organização e apresentação dos dados obtidos. A análise permitiu concluir que as universidades pesquisadas atendem ao requisito da Lei da Inovação onde exigem que elas disponham de um núcleo de inovação tecnológica a fim de gerir a tecnologia produzida. Porém cada universidade possui peculiaridades a respeito de seus processos devido ao ambiente institucional formado e regimentos internos o que acarreta em burocracia para que as empresas tenham acesso à tecnologia.

Palavras-chave: Gestão da Inovação; Transferência de Tecnologia; Patentes. 


\section{INTRODUÇÃO}

A variável tecnológica vem assumindo cada vez mais o papel de promover o tanto o desenvolvimento econômico de um país como a competitividade entre as empresas tornando a inovação uma ferramenta-chave nesses processos. Como demonstração desse fato, observa-se o domínio do mercado por grandes corporações de alta tecnologia (Cohan, 1998).

Para que o desenvolvimento tecnológico chegue ao alcance dos mercados é possível a articulação de diferentes agentes que compõem o sistema nacional de inovação, o desenvolvimento de competências próprias e o estímulo à inovação, gerando nacionalmente produtos de maior valor agregado em um horizonte de tempo menor que o processo de pesquisa e desenvolvimento (P\&D), que depende muito dos resultados para aproximar a inovação das empresas nacionais (Garnica, 2007).

No contexto das políticas públicas dos diferentes países desenvolvidos, a importância entre o setor de ciências e o setor industrial tem se transformado em efetivas ações que visam a transformação de novos conhecimentos em produtos que geram riqueza para o país (Garnica, Vicentim, Entorno, \& Massambani, 2008).

$\mathrm{Na}$ tentativa de explorar melhor o papel da universidade e direcionar a pesquisa ao desenvolvimento do país, em 2004 foi estabelecida a Lei $\mathrm{n}^{\circ}$ 10.973, conhecida como A Lei de Inovação. De acordo com o artigo 17, as ICT (Instituições Científicas e Tecnológicas) do Brasil deverão dispor de um Núcleo de Inovação tecnológica (NIT), com a finalidade de gerir sua política de inovação, dentre outros objetivos, disseminando a cultura da inovação, da propriedade intelectual e da transferência de tecnologia.

Com o surgimento ou fortalecimento dos NIT, a partir da Lei de Inovação (2004), as ICT passaram a contar com uma estrutura capaz de gerir e proteger o seu patrimônio intangível e a desenvolver a competência para realizar a sua transferência para o mercado. Uma ICT bem estruturada é de grande importância para o processo de inovação, visto que as pesquisas realizadas por ela podem resultar em trabalhos literários, gerar criações industriais, programas de computador etc. Por conseguinte, toda atividade intelectual científica e tecnológica possui potencial de gerar conhecimentos, que podem implicar em inovações tecnológicas passíveis de proteção por meio da legislação da propriedade intelectual (Santos, Toledo \& Lotufo, 2009).

Em vista disso, a respeito das ICTs e a gestão de propriedade intelectual, conclui-se que os conhecimentos gerados nas instituições só se transformam em inovação à medida que são disponibilizados à sociedade em geral, por meio de parcerias entre as instituições e as empresas. Então

Revista de Administração e Inovação, São Paulo, v. 12, n.3, p. 28-55, jul./set. 2015. 
é essencial que essas parcerias ocorram visto que se os conhecimentos gerados dentro da instituição não são licenciados ou transferidos, a inovação científica e tecnológica não ocorre, bem como todos os benefícios sociais e econômicos para a sociedade (Araújo, Barbosa, Queiroga, \& Alves, 2010). Esse artigo foi delineado com o objetivo de apresentar uma análise crítica sobre os processos de transferência de tecnologia por meio do processo de licenciamento de patentes das principais universidades brasileiras. A orientação da pesquisa foi definida pela questão central: Como as universidades de ponta brasileiras gerem sua propriedade intelectual a fim de transferir a sociedade?

\section{REFERENCIAL TEÓRICO}

\subsection{A Relação entre universidade e inovação}

A Parceria entre universidade, sociedade e empresas é um processo recente oriundo de um processo de globalização. Com a globalização houve a transformação de hierarquias e hegemonias, sociais e institucionais. Nesse contexto, as universidades, que são vistas como comunidades universais de ideias, ajudaram a construir essas mudanças (Zeleza, 2005).

Com a necessidade das indústrias em incrementar sua política de inovação, necessitando, assim, cada vez mais investir em pesquisa e desenvolvimento, o Governo Federal, por meio dos Ministérios do Desenvolvimento, Indústria e Comércio Exterior, da Fazenda, do Planejamento, da Ciência e Tecnologia, lançou em 26 de novembro de 2003, as "Diretrizes de Política Industrial, Tecnológica e de Comércio Exterior" (PITCE), com o objetivo de aumentar a eficiência econômica, desenvolvimento e a difusão de tecnologias do país, um crescimento de forma sustentável, com a melhoria do bem-estar e da distribuição de renda da população (PITCE, 2009).

Em respostas a essas diretrizes, no ano de 2004 surge a Lei da Inovação que designa universidades, institutos de pesquisa e empresas como agentes produtivos de inovação e tecnologia. Em seu artigo 1, a Lei determina que essas instituições disponham de um Núcleo de Inovação Tecnológica (NIT) próprio ou em associação com outra ICT, com a finalidade de gerir sua política de Inovação.

A Lei da Inovação estabelece várias formas de transferência de tecnologia entre os ICTs (Institutos Científico e Tecnológicos) e o setor produtivo, a saber: a comercialização de criação desenvolvida pelo ICT, a prestação de serviços e o estabelecimento de parcerias, porém como o foco do trabalho está apenas no licenciamento de patentes, também classificado como um meio de

Revista de Administração e Inovação, São Paulo, v. 12, n.3, p. 28-55, jul./set. 2015. 
comercialização de patentes, o termo transferência de tecnologia estará relacionado diretamente a esse tipo de negociação. Para que o licenciamento ocorra, é imprescindível que o NIT adote uma política de difusão de tecnologia que atinja os pesquisadores e a comunidade em geral a fim de que a cultura da inovação venha a ser de cunho social e essa atitude é corroborada pelo Ministério da Ciência e Tecnologia (2011), onde é afirmado que o marco regulatório sobre inovação no Brasil está organizado em torno de três vertentes, a saber: a) constituição de um ambiente propício às parcerias estratégicas entre as universidades, institutos tecnológicos e empresas, bem como uma estrutura interna definida; b) estímulo a participação de instituições de ciência e tecnologia no processo de inovação difundindo a tecnologia entre a sociedade; e c) incentivo à inovação na empresa, demonstrando a importância de se apropriar de uma tecnologia para ganhos de competitividade.

Diante disso, as características de um NIT podem ser resumidas no tripé ilustrado pela figura a seguir:

\section{Figura 1}

Características de um núcleo de inovação tecnológica

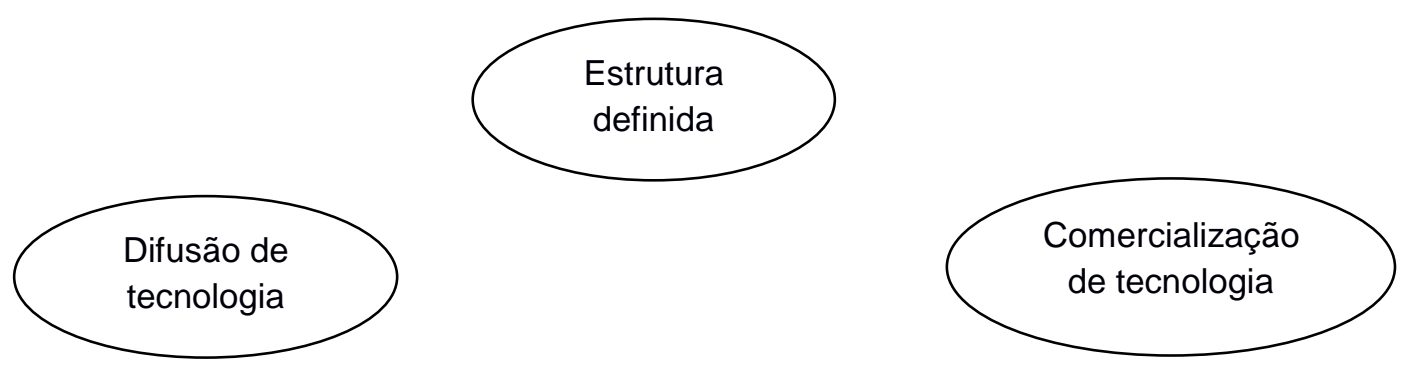

A importância de estudar o processo de inovação das empresas é justificada pelo fato de que esses investimentos em pesquisa e desenvolvimento, tanto dentro da empresa como em parcerias com institutos de pesquisa, retornam à empresa com o aumento do faturamento; em 2004 a cada $\mathrm{R} \$ 1,00$ investido o retorno chegou a $\mathrm{R} \$ 8,50$ (Moreira, 2009).

Apesar do esforço das agências de fomento do governo federal em atribuir importância a inovação, os pressupostos básicos do comportamento do pesquisador pautado em valores tradicionais da comunidade científica e que moldam sua formação ainda direciona seus objetos de pesquisa para a ciência pura em detrimento a pesquisa aplicada.

\subsection{A Transferência de Tecnologia}


A transferência de tecnologia é definida por Villares (2007) como um processo por meio do qual o conhecimento tecnológico passa de uma "fonte" para um "receptor". Cepaluni (2006) assegura que esse conhecimento pode ser transferido de uma fonte para um recebedor de uma forma vertical ou horizontal, e para que haja a transferência real é preciso que a entidade recipiente adquira capacidade de absorver, adaptar e melhorar a tecnologia com certo grau de autonomia.

Inserido no sistema de trocas econômicas e simbólicas da sociedade industrial, o processo de transferência de tecnologia inclui a comunicação da informação tecnológica, pois a tecnologia representa conhecimento científico, técnico, econômico e cultural que torna possível a concepção, planejamento, desenvolvimento, produção e distribuição de bens e serviços (Freire, 1991).

A transferência de tecnologia das universidades para as empresas está inserida em um panorama de cooperação mínima, no qual as empresas buscam novos conhecimentos técnicocientíficos para se manterem competitivas em um mercado com o ciclo de vida cada vez mais curto dos produtos e, as universidades, tradicionais geradoras de novos conhecimentos desejam a aplicação dos mesmos em prol da sociedade, além da possibilidade de se aproximar de problemas de realidade das empresas e auferir recursos adicionais para o desenvolvimento de pesquisas (Garnica, 2007).

Kim (2005) observa que o processo de transferência de tecnologia obedece o mesmo sistema clássico de controle processo, com um (1) ponto de partida, o qual o resultado é desejado; (2) um feedback, que é uma amostra do resultado e (3) uma função comparativa, a qual analisa o ponto de partida e o feedback. Os objetivos da transferência de tecnologia podem ser resumidos da seguinte forma:

a) no intuito de solucionar problemas e gerar ganhos financeiros;

b) pressupondo mudanças na sua extensão que, por vezes vão além das entidades diretamente envolvidas na relação, dado o fato de as transferências de tecnologia ocorrerem em cadeias de valores dentro ou em limites corporativos;

c) quebrando barreiras entre os detentores da tecnologia e os receptores.

O estudo da transferência de tecnologia no Brasil torna-se necessário, visto que conforme Mota (2004), até a década de 1990 as universidades do país adotavam o chamado academicismo que favorecia pesquisas desligadas a realidade do cotidiano, desconhecendo, assim, os problemas ligados à produção e ao mercado.

A universidade transfere tecnologia ao meio externo de diversas formas, e a escolha da forma de fazê-la varia de acordo com a tecnologia específica, as especificidades das tecnologias envolvidas no processo de transferência e o grau de tangibilidade dos processos e métodos. Para Mota (2004), há uma ligação entre a profundidade de conhecimento tecnológico e os modos de transferência, 
principalmente quanto aos mecanismos de transferência adotados. O foco do trabalho buscou analisar como as universidades transferem a tecnologia produzida pelos seus pesquisadores através do licenciamento de patentes.

O desenvolvimento das tecnologias dentro da universidade pode ser realizado sobre duas perspectivas: por meio da inovação guiada pela ciência (science driven innovation) onde a pesquisa é a etapa principal do processo; e pelo caminho da Inovação guiada pelo mercado (market driven innovation), orientado pela demanda empresarial e da sociedade (USP, 2011).

\subsection{O Gerenciamento por Processos}

Não existe um produto, serviço ou informação oferecido por uma empresa sem um processo organizacional (Gonçalves, 2000). Diante disso, torna-se evidente a importância do estudo de gestão por processos para que se possa saber como se dá o processo de transferência de tecnologia das principais universidades brasileiras estudadas e apresentar aspectos positivos e negativos dessa gestão.

Para estudar a gestão por processos, torna-se necessário a definição do que é um processo. De maneira bem simples, Humphrey (2009), define processos como sendo um conjunto de passos para a realização de uma tarefa. O processo deve ser bem definido para que auxilie no planejamento e na execução de um produto ou serviço, ou seja, deve ser descrito suficientemente em detalhes de forma que possa ser consistentemente usado. Porém um processo é mais que um conjunto de passos. Segundo Barbará (2008) os processos são um conjunto de ações ordenadas e integradas para um fim produtivo específico, ao final do qual serão gerados bens e/ou serviços e/ou informações.

Diante dessas definições, a ferramenta administrativa que absorve todas essas ideias é a gestão por processos. Ela pode ser entendida como o enfoque administrativo aplicado por uma organização que busca a otimização e melhoria da cadeia de processos, desenvolvida para atender necessidades e expectativas das partes interessadas, assegurando o melhor desempenho possível do sistema integrado a partir da mínima utilização de recursos e do máximo índice de acerto (Unicamp, 2010).

Uma definição mais operacional que para o termo gestão por processo pode ser: "modelo de gestão organizacional", orientado para gerir a organização com foco nos processos. Esta é uma concepção que pode ser ordem mais prática e mais fácil de trabalhar segundo Barbará, (2008).

Segundo Rummler e Brache (1994), o Gerenciamento de um processo pode ser dividido em 4 etapas: a) o gerenciamento do objetivo; b) o gerenciamento do desempenho; c) o gerenciamento do recurso e d) o gerenciamento da interface. 
Um mapeamento dos processos que torna eficiente a análise do fluxo de informações dos processos de transferência de tecnologias das Universidades estudadas nesse trabalho é o fluxograma, uma ferramenta inestimável para se entender o funcionamento interno e os relacionamentos entre os processos empresariais. Ele é um método que serve para descrever graficamente um processo existente, ou um novo processo proposto, usando símbolos simples, linhas e palavras, de forma a apresentar graficamente as atividades e a sequência no processo (GAV-UFSC, 2003).

Os objetivos de um fluxograma são: mostrar como os elementos se relacionam, permitir a comparação com o processo real, determinar como melhorar a atividade e facilitar a comunicação, ou seja, analisar um fluxograma é adquirir conhecimento sobre o processo, para definir e implementar processos de aperfeiçoamento.

Os tipos de fluxogramas existentes na literatura sobre gestão de processos são: o diagrama de blocos que permite uma rápida noção do processo; o fluxograma padrão que analisa interrelacionamentos detalhados; os fluxogramas funcionais que mostram o fluxo entre organizações ou áreas e os fluxogramas geográficos que mostram os fluxos entre as localidades. Para melhor ilustração dos processos utilizados pelas universidades estudadas adotou-se o fluxograma de diagrama de blocos.

\section{PROCEDIMENTOS METODOLÓGICOS}

Os métodos de pesquisa que foram utilizados no presente artigo foram: o qualitativo e exploratório. O primeiro tem por objetivo entender determinada situação social, fato, papel, grupo ou interação. É um processo investigativo no qual o pesquisador gradualmente compreende o sentido de um fenômeno social ao contrastar, comparar, reproduzir, catalogar e classificar o objeto de estudo (Creswell, 2007). Já o segundo tem como objetivo o aprimoramento de ideias ou a descoberta de intuições e sendo flexível, possibilita a consideração dos mais variados aspectos relativos ao fato estudado. Esse tipo de pesquisa é justificado no trabalho pelo fato do papel dos Núcleos de Inovação Tecnológica (NIT) no Brasil ser considerado um fenômeno recente e há a necessidade de familiarização com o tema a fim de atender os objetivos da pesquisa.

A fim de responder ao objetivo, esse trabalho utilizou como procedimento o método de estudo de multicasos que permite um aprofundamento dos fenômenos estudados para determinar a proximidade com a teoria existente e a compreensão das práticas estudadas.

Depois de identificados os modelos de transferência de tecnologia existente nos NITs estudados, eles serão traduzidos em mapas de processos ou fluxogramas. Esse formato facilitará a

Revista de Administração e Inovação, São Paulo, v. 12, n.3, p. 28-55, jul./set. 2015. 
identificação das atividades, das rotinas e dos processos.

Para a caracterização dos procedimentos das universidades pesquisadas, trabalho utilizou o modelo $5 \mathrm{~W} 1 \mathrm{H}$ para auxiliar a avaliação dos processos que facilitarão a comparação. Essa ferramenta é basicamente um check-list de atividades a serem desenvolvidas que funciona como um mapeamento das mesmas. Basicamente essa ferramenta busca, para cada etapa, a resposta para perguntas como: "O que?”," Quem?”, “Quando?”, “Onde?”, “Por que?” e “Como?” (Maués, 1996).

A amostra dos casos foi definida de forma não probabilística, intencional e por conveniência (Cooper \& Schindler, 2003). O critério de escolha foi o de seleção adotando o ranking de universidades públicas que mais depositaram pedidos de patentes junto ao INPI, ou seja, as universidades que já possuem know-how, nos processos de proteção. Portanto, as universidades escolhidas para o estudo foram a Universidade de São Paulo (USP), Universidade Estadual de Campinas (Unicamp), Universidade de Brasília (UnB) e Universidade Federal de Minas Gerais (UFMG).

Para responder o objetivo de pesquisa foram necessários dois tipos de coletas de dados: coleta de dados secundários e aplicação de questionários a funcionários dos núcleos de inovação tecnológica das universidades estudadas.

\section{RESULTADOS E DISCUSSÕES}

\subsection{O processo de licenciamento de patentes da Universidade de São Paulo}

Com o objetivo geral de identificar, apoiar, promover, estimular e implementar parcerias com o setor privado, governamental, terceiro setor e centros de pesquisa, na busca de resultados para a sociedade a agência USP de Inovação é dividida em Polos por todos os campi, e o campus da capital assume um papel de centralizador das atividades e planejamentos estratégicos. Cerca de 30 pessoas trabalham nos NIT espalhados pelos campi com diferentes vínculos empregatícios, exercendo diversas funções como administrativas e de comunicação.

No caso de patentes, que é o foco do presente trabalho, a Agência USP de inovação desenvolve as chamadas "diligências de inovação", visando priorizar os ativos com maior potencial de transferência e identificar potenciais parceiros para a exploração da tecnologia. São dois os processos de diligências, a saber: a) Diligência de aplicabilidade de formas de proteção; que realiza uma análise criteriosa respeitando os preceitos legais das diferentes formas de proteção às criações e determina a

Revista de Administração e Inovação, São Paulo, v. 12, n.3, p. 28-55, jul./set. 2015. 
forma específica para o registro. b) Diligência do valor inovativo e potencial de mercado; paralelamente ao processo de proteção da tecnologia, a Agência procede a análise técnica do valor inovativo, considerando os impactos para a adoção da tecnologia, seu estágio de desenvolvimento, e tempo estimado para a aplicabilidade em processos industriais. Após o resultado dessas diligências, um Comitê interno de análise procede a indicação da abordagem do mercado para a busca de oportunidades de transferência de tecnologia.

Na USP são três os principais canais de transferência de tecnologia: licenciamento, empresas nascentes e disponibilização das tecnologias via domínio público.

$\mathrm{Na}$ modalidade de licenciamento, as tecnologias geradas no âmbito da Universidade são apresentadas ao mercado para exploração comercial por intermédio de: contato direto com potenciais parceiros da Agência USP de Inovação (empresas, entidade de classes, organizações governamentais e não governamentais), prospecção de novos contatos e indicação dos inventores e publicação no site da Agência USP de Inovação no Banco de Patentes.

Após a verificação de possíveis interessados é aberto um diálogo balizado no interesse da Universidade, da Empresa e da Sociedade. Esse diálogo tem o objetivo de fornecer informações para a elaboração de um modelo de licenciamento que pode ser: a) exclusivo: modalidade de licenciamento em que a empresa é detentora da licença e é a única que pode explorar a patente ou parte desta de acordo com as condições assinadas no contrato e b) não exclusivo: onde poderá existir mais de uma empresa detentora da licença de exploração da patente ou parte desta de acordo com as condições assinadas no contrato.

Esse diálogo vem de encontro à opinião de Gouveia (2008), onde o autor afirma que o país não tem um ambiente propício para a inovação devido à falta de contato entre a universidade e o setor produtivo. O que se observou como resultado da pesquisa é que com relação a USP, o contato entre a empresa e a universidade é feito de modo muito proveitoso, gerando incentivos à pesquisa e inovação bem como evidenciando as necessidades da sociedade.

Definido o modelo e suas condições gerais é realizada a formalização da exploração segundo a legislação brasileira vigente. Para contratos de exclusividade, a agência divulga em seu portal e no diário oficial.

Os resultados financeiros são divididos $50 \%$ para o inventor, 40,5\% para o departamento aplicado em pesquisa, 4,5\% para a unidade e $5 \%$ para a reitoria.

Todos os contratos e convênios são elaborados pela consultoria jurídica da USP, normalmente as negociações de cooperação acontecem por meio de encontros informais, no caso de grandes empresas são formalizados programas e consórcios de pesquisa conjunta (Dudziak, 2007).

Revista de Administração e Inovação, São Paulo, v. 12, n.3, p. 28-55, jul./set. 2015. 
A USP possui parcerias com uma rede ampla de incubadoras de empresas (CIETEC São Paulo, SUPERA em Ribeirão Preto, ParTec em São Carlos, ESALQTec em Piracicaba e UNITec em Pirassununga), além de outras instituições como o SEBRAE, visando promover a aproximação com as chamadas estruturas de apoio, que são os principais lócus de desenvolvimento das empresas.

Diante da realidade apresentada, o processo utilizado pela Universidade de São Paulo se mostrou como uma maneira eficaz de transferência de tecnologia por meio de licenciamentos de patentes.

Com base na análise de cada processo e sub-processo utilizando a ferramenta $5 \mathrm{~W} 1 \mathrm{H}$ foi possível extrair o fluxograma de como o processo de transferência de tecnologia é feito:

\section{Figura 2}

Processos de transferência de tecnologia da USP

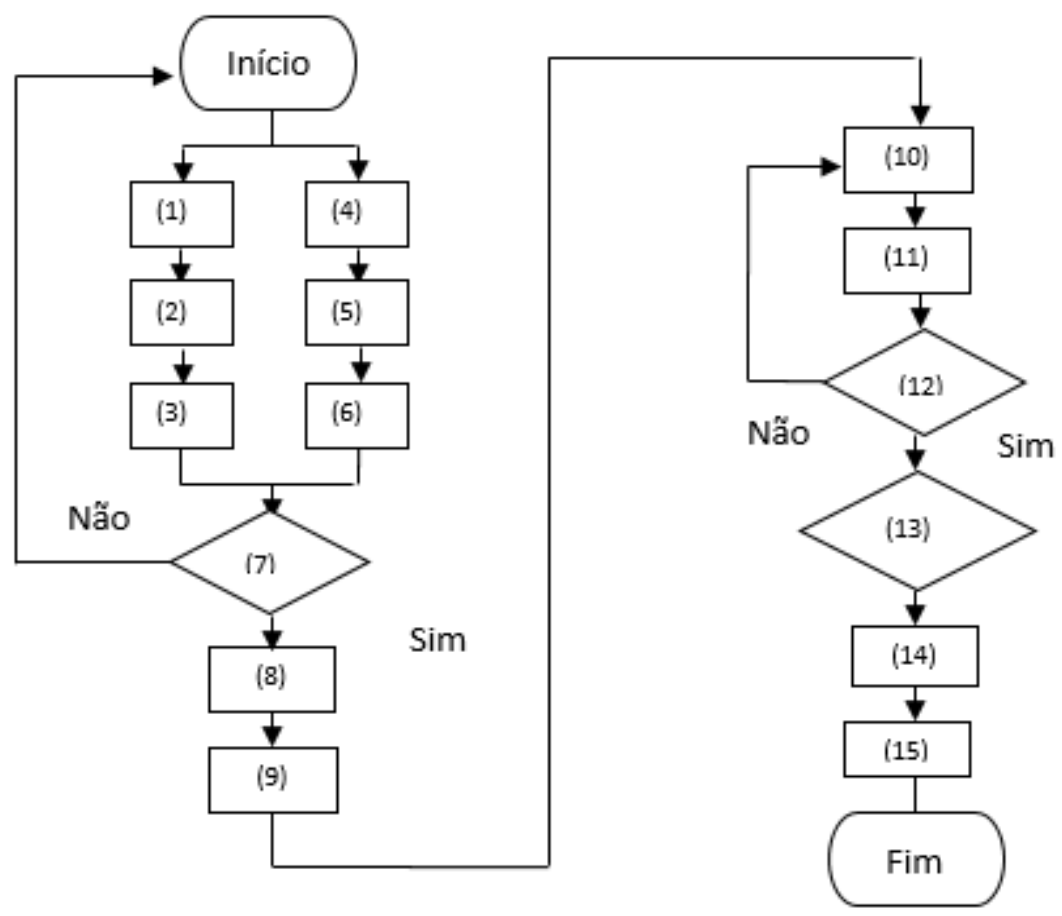

Fonte: Elaborado pelos autores, 2014.

Legenda: (1) Diligência de Aplicabilidade de formas de proteção; (2) Preceitos legais; (3) Formas de Registro; (4) Diligência do valor inovativo e potencial de mercado; (5) Análise técnica do valor inovativo; (6) Potencial de mercado; (7) É passível de proteção?; (8) Indicação do mecanismo de proteção de tecnologia e estratégia de comercialização; (9) Comitê de análise; (10) Banco de patentes; (11) Apresentação de mercado; (12) Foi licenciado?; (13) É exclusivo? (14) Contrato; (15) Condições de Licenciamento (prazo, pagamento). 
As variáveis principais investigadas no questionário foram estudadas e assim foi possível identificar gargalos e atividades estruturadas que favorecem o processo de proteção da USP. Com essas informações foram evidenciados os pontos em que a universidade tem facilidades e dificuldades no processo de transferência de tecnologia.

\section{Quadro 01}

Avaliação das variáveis no processo de licenciamento de patentes da USP

\begin{tabular}{|l|l|}
\hline Difusão da tecnologia & $\begin{array}{l}\text { É considerado um ponto positivo da USP por } \\
\text { conseguir ter um alto nível de parcerias, eventos e } \\
\text { um site bem organizado. }\end{array}$ \\
\hline Comercialização & $\begin{array}{l}\text { Apresenta pontos relevantes por utilizar elementos } \\
\text { do marketing industrial. Porém no quesito } \\
\text { valoração e celebração de convênio a agência } \\
\text { apresenta algumas defasagens. }\end{array}$ \\
\hline Estrutura interna & $\begin{array}{l}\text { A agência não possui total liberdade para efetuar as } \\
\text { negociações, porém a mão-de-obra e o espaço físico } \\
\text { que possui é considerado ótimo para execução das } \\
\text { atividades. }\end{array}$ \\
\hline
\end{tabular}

Fonte: Elaborado pelos autores, 2014.

Como ponto positivo é evidenciado a política da Universidade em efetivar parcerias para a transferência de tecnologia. Todo pesquisador que possui uma tecnologia protegida é incentivado pela Universidade e pela agência a transferir sua tecnologia, participar das reuniões e ter contato com as empresas interessadas. Esse mecanismo é facilitado pela possibilidade de remuneração do pesquisador, caso sua tecnologia seja transferida. Assim tanto a Universidade, quanto o pesquisador sentem-se incentivados a desenvolver cada vez mais pesquisas que atinjam diretamente o bem-estar da sociedade.

Os pontos negativos do processo de transferência de tecnologia da USP estão principalmente relacionados aos tempos e prazos para as celebrações de contrato, uma vez que a empresa já demonstrou interesse pela tecnologia ou já venceu o processo de licitação para a exploração da mesma. A Agência USP de Inovação não tem autonomia para gerir os contratos de TT, uma vez que estes devem ser avaliados pelo comitê jurídico da Universidade, o que acarreta em atraso para a celebração do acordo. Outro ponto negativo que foi encontrado nesse processo é que a valoração da tecnologia não segue um padrão específico, ficando a cargo dos avaliadores levarem em consideração principalmente os custos contábeis que a pesquisa teve, deixando de lado os ganhos econômicos que a tecnologia pode trazer no âmbito do impacto da inovação nos mercados e na sociedade.

\subsection{O processo de licenciamento de patentes da Universidade de Campinas}


A agência de Inovação Inova Unicamp é a responsável pela gestão da propriedade intelectual, especialmente de patentes e outras formas de PI passíveis de proteção legal, pelo estabelecimento de parcerias entre a Unicamp e empresas, pelo apoio técnico a projetos cooperativos, estabelecimento de parcerias estratégicas de médio e longo prazo com entidades públicas e privadas com foco na inovação e no conhecimento, pelo estímulo a criação de novas empresas de base tecnológica e pelas transferências de tecnologias protegidas da Unicamp, por meio de apoio ao registro, licenciamento e comercialização dos resultados de pesquisas.

Atualmente a agência é composta por uma Diretoria de 5 pessoas, 9 profissionais da área técnica e mais 5 da área administrativa. Ainda são membros da equipe INOVA mais 27 pessoas entre bolsistas de projetos aprovados junto a agências de fomento, ligados à fundação e outras parcerias. A estrutura organizacional foi definida pela legislação supra mencionada, sendo que há quatro divisões principais: Diretoria Executiva, Diretoria de Desenvolvimento de Parcerias, Diretoria de Propriedade Intelectual e Diretoria de Parques Tecnológicos e Programas de Incubadoras de Empresas de Base Tecnológica.

Quanto ao processo de licenciamento de patentes, a Agência tem um papel importante para o sucesso dessa ação. Após a geração da tecnologia e o pedido de depósito de patente efetuado junto ao INPI, a agência Inova Unicamp age na publicação da tecnologia junto às empresas parceiras através de reuniões, eventos e divulgação em seu endereço na Internet. Essa divulgação apresenta o composto de marketing industrial (importante ferramenta utilizada), onde a preocupação com o cliente e a compra organizacional é de grande importância para o sucesso da transferência.

Quando surge o interesse por alguma empresa no produto, tecnologia ou serviço gerado pela Universidade, esta procura a Agência para demonstrar a importância em se apropriar da tecnologia em questão.

Após o estudo das necessidades da empresa, uma equipe é acionada para formalizar um contrato de utilização da tecnologia em questão. Nessa etapa são definidos os critérios para a transferência da tecnologia tais como a exclusividade da empresa na apropriação dessa tecnologia, os valores a serem pagos e a destinação da verba envolvida na negociação.

O papel do NIT nessa negociação é essencial do ponto de vista dos resultados obtidos com as negociações de contratos com empresas A atuação dessa estrutura propicia maior volume de negociações de contratos e eficiência na comercialização de tecnologia da universidade. Com isso, não é onerado o tempo gasto pelo inventor com a pesquisa, mas, por outro lado, com a negociação sendo gerada por estruturas competentes gera-se royalties maiores. 
Diferentemente do encontrado no processo de transferência de tecnologia da USP, na Unicamp a variável "difusão de tecnologia" é o forte da agência. Através de seu website é disponibilizado o banco de patentes disponíveis e assim a consulta fica facilitada por qualquer interessado. Os eventos e treinamentos feitos pela agência também fazem com que a sociedade tenha maior contato com os pesquisadores. Há também uma equipe de transferência de tecnologia que trabalha em estreita relação com os inventores e com a indústria.

No quesito "comercialização" a agência Inova Unicamp também possui vantagens dentre as demais universidades pesquisadas. Ela possui uma equipe que determina o "preço" pago pela empresa para licenciar uma tecnologia da universidade, quando essa é protegida, ou a determinação de "royalties", remuneração ou outros benefícios financeiros que resultam da transferência de tecnologia da universidade, seja ela direta ou por terceiros, tudo isso dentro do ambiente legal no qual a universidade se insere.

A estrutura dos processos internos da agência Inova Unicamp também é de ótima qualidade, o espaço físico é ideal para reuniões com as empresas parceiras e a mão de obra é qualificada e de quantidade suficiente para atender a todas as etapas de transferência de tecnologia, divididas dentre os setores que foram especificados acima.

Como resultado da aplicação da ferramenta $5 \mathrm{~W} 1 \mathrm{H}$ foi possível montar o fluxograma do processo de transferência de tecnologia da Universidade de Campinas, conforme apresentado abaixo:

Figura 03

Processo de transferência de tecnologia da Unicamp 


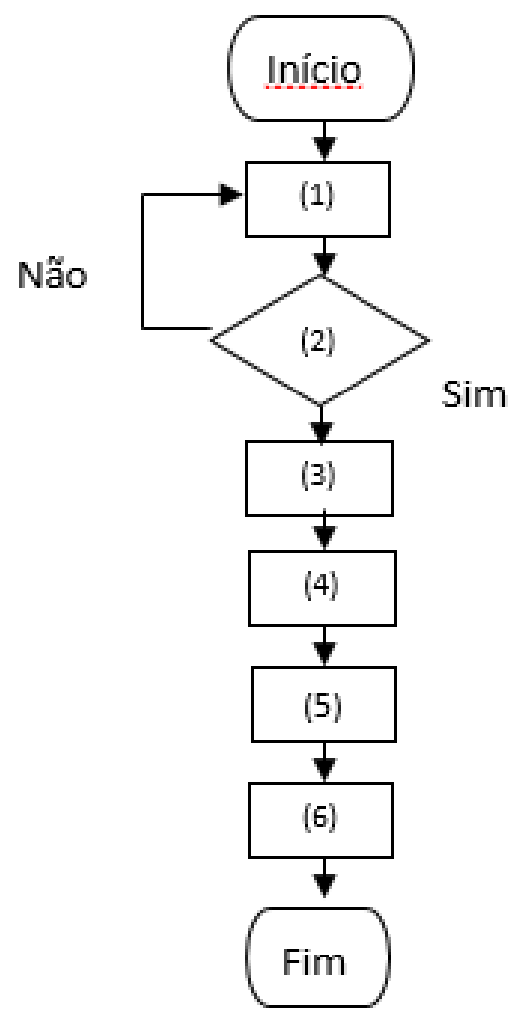

Nota. Elaborado pelos autores, 2014.

Legenda: (1) Divulgação na comunidade; (2) Alguma empresa interessada?; (3) Negociação com as empresas; (4) Análise do segmento-alvo; (5) Formalização do contrato; (6) Acompanhamento e Implementação.

A análise do fluxograma permitiu avaliar as variáveis estudadas no processo de transferência de tecnologia da Unicamp. Esses aspectos estão apresentados no quadro abaixo.

\section{Quadro 02}

Avaliação das variáveis no modelo TT da Unicamp

\begin{tabular}{|l|l|}
\hline Difusão de tecnologia & $\begin{array}{l}\text { Os pesquisadores são muito incentivados a gerar } \\
\text { pesquisa e produtos de tecnologia. A agência está } \\
\text { relativamente aberta a sociedade para conhecimento } \\
\text { das atividades }\end{array}$ \\
\hline Comercialização da tecnologia & $\begin{array}{l}\text { Independência da Agência perante a Universidade } \\
\text { para a negociação }\end{array}$ \\
\hline Estrutura interna & Muito bem definida \\
\hline
\end{tabular}

Nota. Elaborado pelos autores, 2014.

Como pontos positivos do processo de transferência de tecnologia da Unicamp, pode-se observar que a agência Inova Unicamp tem maior autonomia no que tange aos processos decisórios da transferência de tecnologia, bem como do procedimento legal. A Universidade só dá o aval técnico de 
que a Agência necessita. Observou-se também que as reuniões tanto entre os técnicos da agência, entre os pesquisadores e o mercado são cada vez mais frequentes, o que facilita o processo de transferência de tecnologia.

A agência também leva vantagem nos processos legais e decisórios visto que ela possui certa autonomia para as negociações. Os preços e o modo como é transferida a tecnologia é bem definido pela equipe da agência.

\subsection{O processo de licenciamento de patentes da UnB}

$\mathrm{Na}$ UnB, o Núcleo de Inovação Tecnológica é o Centro de Apoio ao Desenvolvimento Tecnológico (CDT). Este órgão foi criado em 1986, e está vinculado à reitoria da universidade, sendo gestor do Parque Científico e Tecnológico da UnB. O CDT é incentivador da inovação tecnológica no Brasil e apoia a pesquisa e o desenvolvimento do empreendedorismo, além de fortalecer laços existentes entre a sociedade, empresas e governo. As atividades do CDT são estabelecidas a partir de quatro eixos de atuação: Ensino, Pesquisa e Difusão do Empreendedorismo, Transferência e Comercialização de Tecnologias e Desenvolvimento Empresarial e Cooperação institucional.

O CDT desenvolve atividades não identificadas no processo de sensibilização e identificação das inovações tecnológicas, que é o mapeamento da universidade por meio de visitas aos laboratórios. É importante destacar que esse contato não é único, ele acontece semestralmente com novas visitas, o que permite acompanhar as pesquisas e identificar antecipadamente na sociedade a aplicabilidade da mesma.

Esse trabalho contribui também com os outros programas do centro, a Multincubadora, o Empreend, o Programa Jovem Empreendedor, o Serviço Brasileiro de Respostas Técnicas (SBRT), o Disque Tecnologia, o Programa Empresa Junior, o Núcleo e Credenciamento de Laboratórios (NACLI), o Núcleo de Inteligência competitiva e o NUPITEC (Serra, 2010).

Esses programas são focados na interação universidade, empresa e governo, e uma forma de fortalecer essa relação foi por meio da criação do NUPITEC em 1999 pela Resolução UnB 005/98. De acordo com Beltrão (2008, p.80) o “[...] Núcleo já apoiou mais de dez laboratórios e atua com resultado preciso, qualidade garantida e certificação Inmetro”.

Além de ser uma instituição que apoia projetos que beneficiam diretamente a população com ações relacionadas à tecnologia, empreendedorismo, inovação, associativismo e cooperativismo, o CDT é responsável pelo desenvolvimento econômico e consolidação de negócios, gerando trabalho, renda e sustentabilidade (UNB, 2011).

Revista de Administração e Inovação, São Paulo, v. 12, n.3, p. 28-55, jul./set. 2015. 
No quesito transferência de tecnologia à sociedade, a UnB possui, desde 1989, a incubadora denominada, em 2004, com Multincubadora de Empresas, esse programa permite ao meio acadêmico e à comunidade local assessoria gerencial para o desenvolvimento de novos empreendimentos. Algumas áreas do conhecimento permitem ao pesquisador desenvolver inovações tecnológicas, porém, nem sempre possuem conhecimento específico de como levá-las até a sociedade.

Conforme dito anteriormente, CDT é dividido em eixos de atuação que cuidam desde o início da pesquisa até a transferência de tecnologia. O eixo da Transferência de Tecnologia envolve o programa Disque Tecnologia, o Núcleo de Propriedade Intelectual e Transferência de Tecnologia, a Agência de Comercialização de Tecnologia e os projetos do Parque Científico e Tecnológico e do Serviço Brasileiro de Respostas Técnicas.

O núcleo de Propriedade Intelectual auxilia o pesquisador, estudante, ou técnico administrativo a proteger sua invenção e disponibilizar esse conhecimento a sociedade. Essa parte do processo de inovação é abordada por Serra (2010), onde ela estuda o processo desde o início da pesquisa até a proteção da tecnologia.

Já a agência de Comercialização de Tecnologia, promove a transferência das tecnologias de titularidade da Universidade de Brasília. Essa agência atua na negociação com o setor produtivo, na avaliação e valoração da tecnologia e na formalização e gestão dos instrumentos jurídicos. É através dessa agência que foram encontrados os elementos do composto de marketing industrial, adotados pela Universidade, tais como a precificação do produto; a análise de compra organizacional das empresas interessadas nas tecnologias disponíveis na UnB e a distribuição dessa tecnologia, como contratos de exclusividade, e os "royalties" pagos.

Abaixo segue o fluxograma dos processos de transferência de tecnologia da UnB:
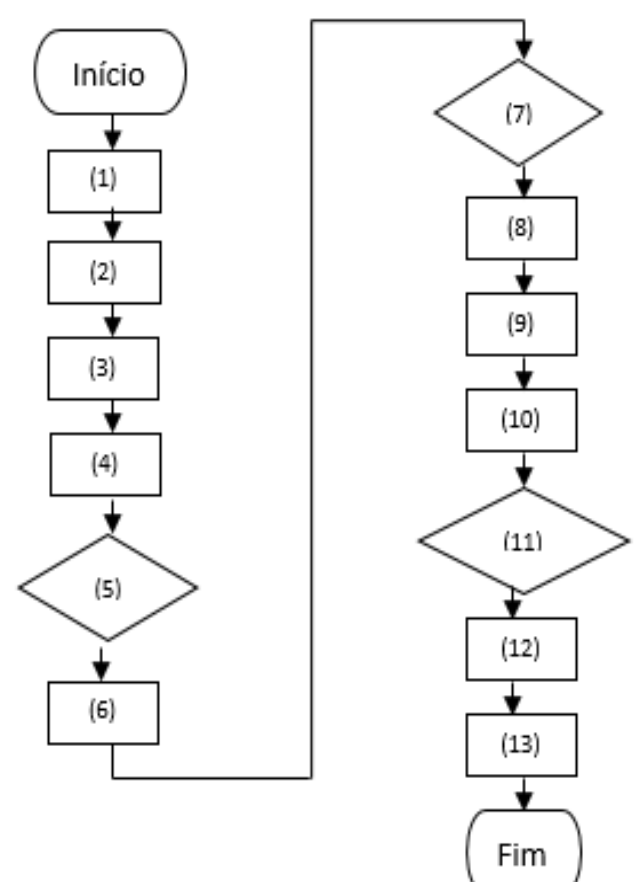

gura 04

ocesso de transferência de tecnologia da UNB 
Nota. Elaborado pelos autores, 2014.

Legenda: (1) Divulgar tecnologia; (2)Visitas técnicas; (3)Oportunidade de mercado; (4)Avaliação de tecnologia; (5)É passível de transferência?; (6) Valoração da tecnologia; (7)Empresa se interessa pela tecnologia?; (8) Negociação; (9) Instrumentos Jurídicos; (10) Formalização de Contratos; (11) Licença exclusiva?; (12) Licitação; (13) Acompanhamento.

Como pontos positivos do processo de transferência de tecnologia, pode-se observar que, pelo menos, ao que foi disponibilizado pela agência, os processos de difusão de tecnologia não estão bem definidos. Já quanto ao processo de comercialização da tecnologia e aos processos internos, a UnB apresenta destaque com relação as outras universidades estudadas, visto que a agência possui um setor específico para a valoração da tecnologia, e os processos internos da agência também se encontram bem definidos.

\section{Quadro 03}

Avaliação das variáveis de TT no modelo da UNB

\begin{tabular}{|l|l|}
\hline Difusão de tecnologia & $\begin{array}{l}\text { Não são identificados no processo porém há } \\
\text { visitas aos pesquisadores pelo menos uma vez ao } \\
\text { semestre. }\end{array}$ \\
\hline Transferência de tecnologia & $\begin{array}{l}\text { Possui um setor específico para a valoração da } \\
\text { tecnologia e definição dos pagamentos e e } \\
\text { royalties. }\end{array}$ \\
\hline Processos internos & $\begin{array}{l}\text { A agência é distribuída em setores delegando as } \\
\text { fuções entre os diversos núcleos. Os processos } \\
\text { são bem definidos. }\end{array}$ \\
\hline
\end{tabular}

Fonte: Elaborado pelos autores, 2014.

\subsection{O processo de licenciamento de patentes da UFMG}


Na UFMG, com relação ao processo de difusão de tecnologia, a agência é bem semelhante à Agência USP de Inovação. Com a finalidade de provocar a sensibilização acadêmica para a ciência e tecnologia, a Coordenadoria de Transferência e Inovação Tecnológica (CTIT) desenvolve uma série de eventos que disseminam a cultura de propriedade intelectual favorecendo o processo de identificação de inovações tecnológicas e de elaboração do processo de transferência de tecnologia pelo próprio pesquisador-inventor da tecnologia. Os eventos que o CTIT realiza têm como público-alvo a comunidade discente, docente e funcionários da UFMG, sendo realizados periodicamente cursos, palestras e treinamentos. São distribuídos também materiais impressos como panfletos, cartilhas e manual de boas práticas e notas de boletim - UFMG que é distribuído na universidade semanalmente (Serra, 2010).

Na UFMG uma tecnologia pode ser transferida de 3 formas: através da chamada transferência de tecnologia, da transferência de materiais e dos contratos com a indústria.

Com relação ao processo de transferência de tecnologia da Universidade Federal de Minas Gerais, acontece uma peculiaridade. $\mathrm{O}$ setor de Transferência de Tecnologia da agência inicia seu trabalho assim que o pesquisador apresenta seu estudo, a fim de obter a análise de proteção, ou seja, se a pesquisa é passível de gerar alguma propriedade intelectual ou não. Junto à análise de proteção, o CTIT realiza um estudo mercadológico utilizando bases de dados específicas no intuito de avaliar o potencial de mercado que a possível tecnologia gerada pela pesquisa pode oferecer. Desse modo, caso haja um interesse de alguma empresa em se apropriar da tecnologia, os contratos e negociações são realizados antecipadamente, fazendo com que a transferência seja mais eficaz.

As tecnologias disponíveis para a indústria estão relacionadas no Banco de patentes da UFMG. Quando há interesse da parte de uma empresa em uma tecnologia específica, informações adicionais sobre ela poderão ser solicitadas mediante um contrato de sigilo com a agência.

Quando há uma transferência de tecnologia e de materiais na Universidade, esta é licenciada mediante o pagamento de licenciamento e de "royalties". As taxas pagas são divididas em partes iguais entre a UFMG, titular da patente, e inventores. A divisão entre os inventores será feita seguindo acordo prévio feito entre eles. Para que o processo de transferência se inicie é necessário que a divisão de assessoria jurídica da CTIT seja acionada para acompanhar todo processo de licenciamento.

Adicionalmente, o licenciamento poderá também resultar em financiamento para um projeto de pesquisa patrocinado pelo licenciado, como pagamento pela licença ou parte dele.

Na difusão da tecnologia, a interação com a comunidade acadêmica é feita sempre que aparecem mudanças legais ou simplesmente para receber um feedback da mesma para aprimorar os

Revista de Administração e Inovação, São Paulo, v. 12, n.3, p. 28-55, jul./set. 2015. 
trabalhos e para melhor atendê-la. Segundo dados da UFMS (2011), 71\% dos inventos em processo de patente tem participação dos alunos além de ser um meio de formar pessoas e preservar o know-how.

\section{Figura 05}

Processo de transferência de tecnologia da UFMG

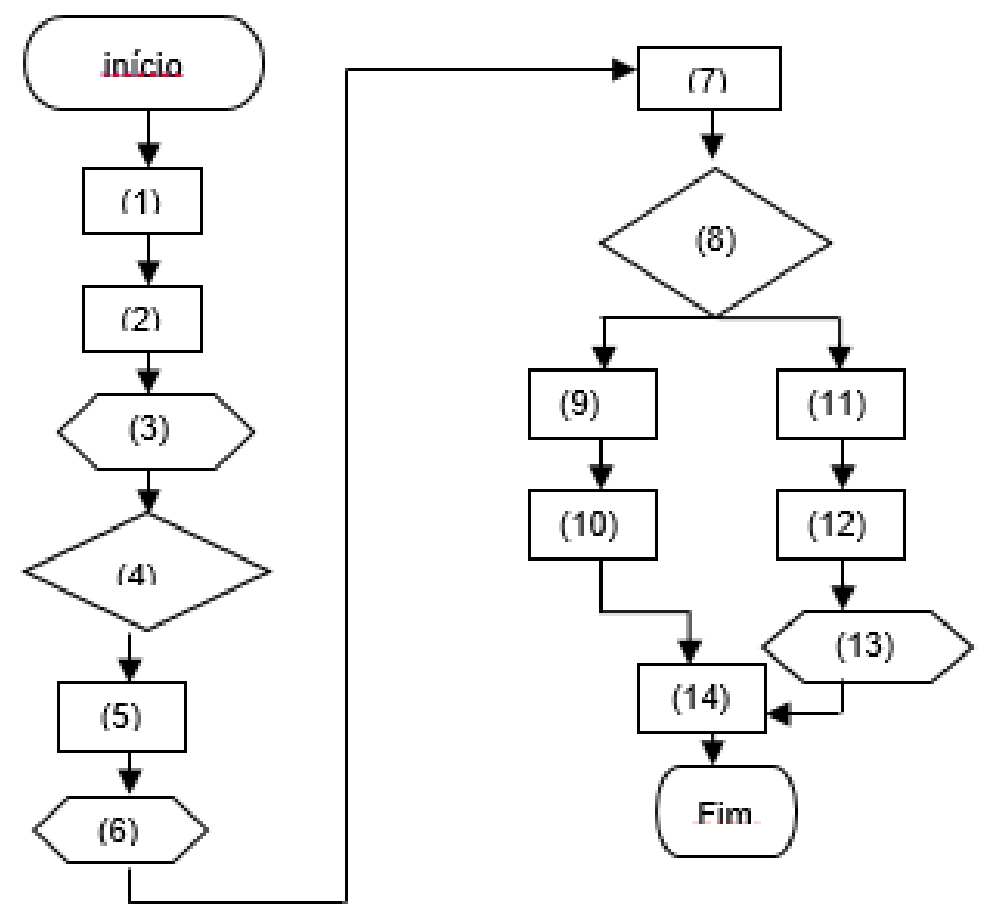

Fonte: Elaborado pelos autores, 2014.

Legenda: (1) Divulgar tecnologia; (2) Contato com as parcerias; (3) Analisar demanda das empresas; (4)Há alguma empresa interessada?; (5) Receber empresa interessada; (6) Analisar propostas de licenciamento; (7) Estudo jurídico para amparo legal; (8) Foi solicitado exclusividade?; (9) Negociar contrato; (10) Assinar contrato; (11) Divulgar edital; (12) Receber propostas; (13) Analisar propostas de financiamento; (14) Transferir tecnologia.

Outro ponto relevante do CTIT, com relação aos outros processos de transferência de tecnologia estudados é que o pesquisador sempre tem retorno mesmo que a tecnologia não atenda aos requisitos de proteção, já que a tecnologia poderá ser transferida à sociedade por meio de transferência de know-how. Um ponto que pode ser considerado como negativo dentro do CTIT é que todo o processo de transferência de tecnologia é realizado pela agência, incluindo a busca e redação de patentes. Isso acarreta em maior gasto para manter uma equipe multidisciplinar específica dentro da agência. 


\section{Quadro 04}

Análise das variáveis no modelo de TT da UFMG

\begin{tabular}{|l|l|}
\hline Difusão de tecnologia & $\begin{array}{l}\text { Equipe multidisciplinar que acompanha os projetos } \\
\text { desde o início }\end{array}$ \\
\hline Comercialização de tecnologia & $\begin{array}{l}\text { A transferência de tecnologia já detecta a possível } \\
\text { comercialização antes mesmo de o depósito de } \\
\text { patente ser efetuado }\end{array}$ \\
\hline Estrutura interna & $\begin{array}{l}\text { Ampla multidisciplinaridade dos funcionários. Não } \\
\text { há setores específicos dentro da agência. }\end{array}$ \\
\hline
\end{tabular}

Nota. Elaborado pelos autores, 2014.

\subsection{Comparação entre os modelos de Transferência de Tecnologia}

Com a pesquisa foi obtido todos os dados necessários para que fosse possível a elaboração dos processos de transferência de tecnologia acima mostrados. Há algumas diferenças importantes notadas na pesquisa já com relação à obtenção de dados. No caso da USP e da Unicamp, por exemplo, os dados são de fácil acesso já que estas universidades dispõem de um trabalho de divulgação anual de seus dados estatísticos. Outras universidades, como o caso da UFMG, ainda não possuem esses dados disponíveis para pesquisadores em seus meios de comunicação, porém os dados foram extraídos de outras fontes como o INPI, a CAPES e o CNPq, o que não acarretou em dificuldades para execução do trabalho.

Fato interessante também notado na pesquisa é que a complexidade de busca de dados científicos das universidades se reflete na busca pelo banco de patentes de suas agências de inovação. Enquanto a USP oferece um website específico com seu banco de patentes, no caso da UnB as patentes só foram encontradas mediante consulta ao INPI, o que pode impedir o contato com possíveis empresas parceiras.

Diante disso, o gráfico abaixo ilustra o total da produção científica das universidades pesquisadas. Observa-se que a USP é a universidade que mais produz em termos científicos dentre os dados da amostra. Já a UnB e a UFMG possuem uma produção científica similar, o que é refletido em seus processos de transferência de tecnologia, conforme mostrado a seguir:

\section{Figura 06}

Relação da produção científica entre as universidades pesquisadas no ano de 2011 


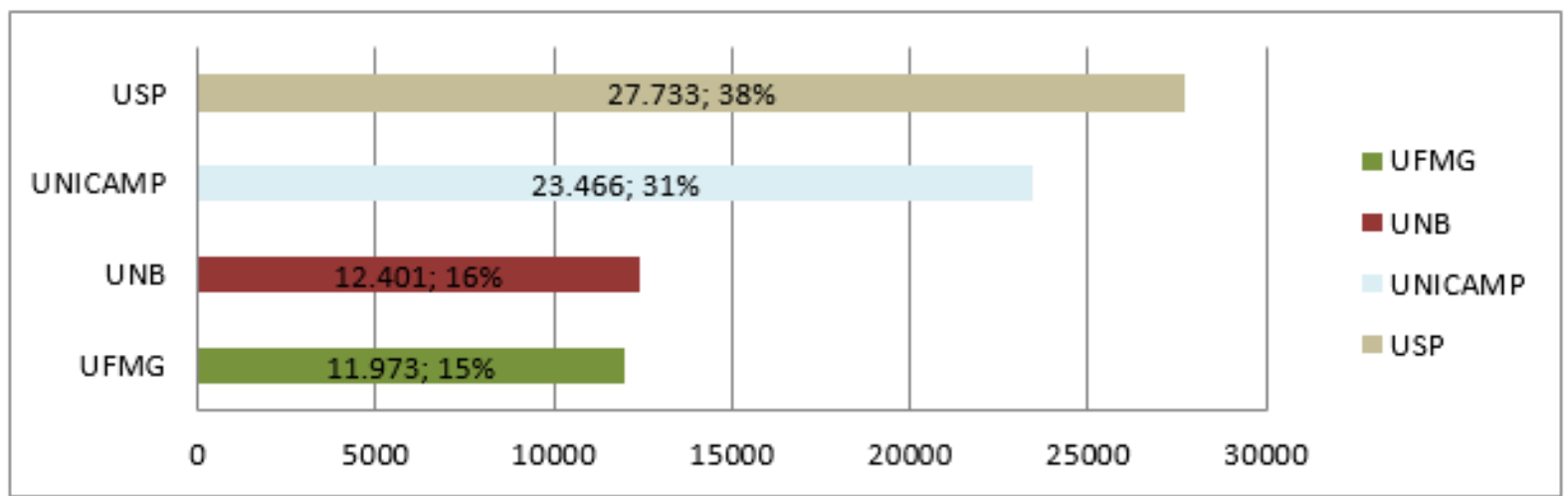

Nota. Elaborado pelos autores a partir de dados dos anuários estatísticos das universidades, 2014.

Esse gráfico, acompanhado da ilustração a seguir, fornece dados interessantes sobre a geração de patentes das universidades. Nota-se que possivelmente há uma relação entre a produção científica da instituição e os pedidos de depósitos de patentes. Novamente a USP fica na frente como a universidade que mais entrou com pedidos de depósitos de patentes no ano de 2011, foram 96 pedidos no total, de acordo com o INPI (2012). Esse fato afirma que para que ocorra a inovação tecnológica, as universidades devem primeiramente produzir conhecimento científico e só depois, com ajuda de órgãos específicos, devem transformar esse conhecimento científico em inovação para a sociedade.

É possível notar também que as universidades que tiveram no ano de 2011 números semelhantes em produção científica, também tiveram o mesmo comportamento no que tange aos pedidos de depósitos de patentes. Segundo o INPI (2012), a UFMG teve 10 pedidos depósitos de patentes e a UnB teve 11. A Unicamp também possui grande representatividade em produção científica e depósitos de patentes, chegando a ultrapassar a USP no número de pedidos de patentes. Porém no ano de 2011 a Unicamp ficou em segundo lugar entre as universidades públicas brasileiras e também dentre a amostra da pesquisa.

O gráfico a seguir ilustra a relação percentual de pedidos de depósitos de patentes entre as universidades pesquisadas. No ano de 2011, a USP ficou com mais da metade dos pedidos dentre as instituições estudadas.

\section{Figura 06}

Pedidos de depósitos de patentes junto ao INPI das universidades pesquisadas no ano de 2011 

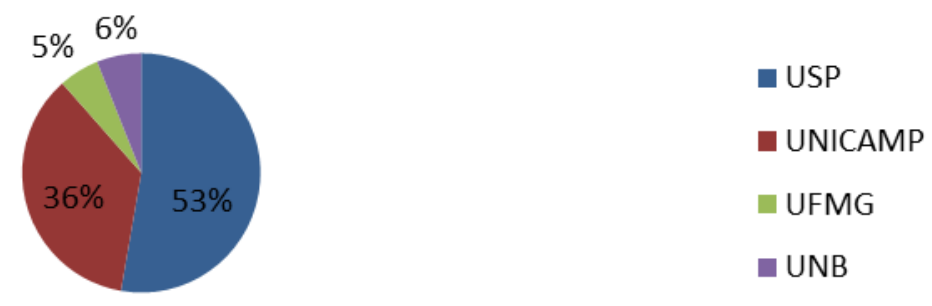

Nota. Elaborado pelos autores a partir de dados do INPI, 2014.

Como dito anteriormente, os processos de transferência de tecnologia das universidades da amostra foram desenhados a partir de dados primários oriundos dos questionários aplicados aos funcionários das agências. A USP possui o modelo mais complexo para a transferência de tecnologia, devido ao fato de ser a maior agência dentre as estudadas e possuir o maior quadro funcional. A Unicamp possui o menor modelo desenhado como resultado da pesquisa. Isso se deve ao fato de a equipe estar organizada em partes dentro desse processo, ou seja, os responsáveis pela transferência de tecnologia são apenas uma parte do quadro funcional da agência. Já os modelos da UnB e da UFMG se apresentam de forma semelhante, tanto em complexidade quanto ao tamanho do quadro funcional. Isso se deve ao fato de que essas agências ainda não possuem um fluxo de pedidos de depósitos suficientemente grande que justifique um processo mais elaborado.

A comparação entre os modelos de transferência de tecnologia foi elaborada de acordo com a tabulação dos resultados de análise das instituições que podem ser resumidas a partir de 3 variáveis principais, a saber: Difusão de tecnologia, Comercialização e a Estrutura Interna, conforme definido pelo Ministério de Ciência e Tecnologia e apresentado no referencial.

As estruturas no processo de transferência de tecnologia apresentam algumas semelhanças e diferenças entre si. Diante do processo de difusão de tecnologia a USP surge como destaque já que os seus processos estão bem definidos e agência trabalha com eventos para atrair interessados em inovação. O website da agência também é um diferencial onde se pode encontrar informações fundamentais para o fomento inovativo das empresas. Já a Unicamp tem um trabalho veemente no incentivo a pesquisadores para geração de pesquisa e produtos de tecnologia, porém diferentemente da USP a agência de inovação não está aberta facilmente a comunidade em geral, já que empresas interessadas em inovação tecnológica apresentam alguns entraves burocráticos a fim de celebrar um convênio, por exemplo. Vale ressaltar aqui que no que tange as informações sobre pesquisa, desenvolvimento e tecnologia, a Unicamp se encontra totalmente aberta aos pesquisadores. Particularmente, a UnB não apresenta um programa efetivo de difusão de tecnologia, porém isso não quer dizer que eles não incentivam seus pesquisadores já que, pelo menos, uma vez ao semestre há um

Revista de Administração e Inovação, São Paulo, v. 12, n.3, p. 28-55, jul./set. 2015. 
levantamento das pesquisas dentro da instituição. Por último tem-se a difusão de tecnologia da UFMG que acompanha os projetos multidisciplinares dos pesquisadores desde o início, direcionando a mesma para geração de tecnologia e inovação. Ou seja, o processo de difusão de tecnologia reflete nos números de depósitos de patentes, quanto mais organizada é a agência nesse quesito, maiores são as chances de se gerar tecnologia e transferi-la a sociedade.

Com relação à comercialização de tecnologia, a USP analisa diversos aspectos do comportamento de compra dos interessados, porém há um entrave no que se refere a valoração da tecnologia, ou seja, o quanto ela vale de fato e quais os retornos que ela pode trazer. Esse problema já não é encontrado na Unicamp e na UnB já que as agências possuem equipes que trabalham somente com essa comercialização e na valoração da tecnologia. A agência de inovação da Unicamp possui ainda certa autonomia na comercialização dentro do processo, ou seja, a comercialização é independente da universidade. Na UFMG a comercialização da tecnologia envolve toda agência que por ser composta por uma equipe multidisciplinar, não possui uma equipe específica para tal fim. A mesma equipe que foi a responsável pela pesquisa, pode ser também a responsável pela negociação e transferência da tecnologia, cabendo à agência a resolução dos entraves legais.

No que se refere a estrutura interna das agências pesquisadas, todas as universidades envolvidas na pesquisa cumprem o requisito da Lei da Inovação de 2004 onde elas devem dispor de um NIT para gerir a inovação tecnológica. Porém cada universidade possui sua particularidade e os processos acabam por respeitar o ambiente institucional e a legislação que possuem. Na USP o espaço físico é ideal para gerir tecnologia, com espaços para reuniões e infraestrutura necessária para os funcionários. Igualmente a USP, a Unicamp também possui estrutura interna bem definida, com funcionários especializados em cada etapa do processo de transferência. Diferentemente das outras universidades estudadas, o processo de transferência de tecnologia da UnB está bem definido, porém a agência se encontra dividida em setores independentes que juntos conseguem gerir a inovação tecnológica para a sociedade. Já a UFMG apresenta uma agência diferente da encontrada na UnB, lá não há setores específicos dentro da agência visto que a multidisciplinaridade dos funcionários da agência não torna a divisão uma questão essencial para o bom funcionamento da mesma.

Abaixo segue um quadro-resumo das características relevantes dentro do processo de transferência de tecnologia das universidades pesquisadas:

\section{Quadro 05}

Quadro-resumo das características dos modelos de transferência de tecnologia das instituições

\begin{tabular}{l|l|l|l} 
USP & Unicamp & UnB & UFMG \\
\hline
\end{tabular}

Revista de Administração e Inovação, São Paulo, v. 12, n.3, p. 28-55, jul./set. 2015. 


\begin{tabular}{|c|c|c|c|c|}
\hline $\begin{array}{ll}\text { Difusão } & \text { de } \\
\text { tecnologia } & \end{array}$ & $\begin{array}{c}\text {-Eventos } \\
\text { periódicos } \\
\text {-Website bem } \\
\text { desenvolvido }\end{array}$ & $\begin{array}{l}\text {-Incentivos a } \\
\text { pesquisadores } \\
\text {-Restrições } \\
\text { burocráticas de } \\
\text { acesso }\end{array}$ & $\begin{array}{l}\text {-Toda a equipe } \\
\text { participa do } \\
\text { processo de } \\
\text { difusão de } \\
\text { tecnologia }\end{array}$ & $\begin{array}{l}\text {-A multidisciplinari- } \\
\text { dade da agência é o } \\
\text { ponto forte }\end{array}$ \\
\hline Comercialização & $\begin{array}{l}\text {-Dificuldade de } \\
\text { valoração da } \\
\text { tecnologia }\end{array}$ & $\begin{array}{c}\text {-Processo de } \\
\text { valoração bem } \\
\text { definido } \\
\text {-Independência da } \\
\text { agência }\end{array}$ & $\begin{array}{l}\text {-Possui equipe } \\
\text { especialista em } \\
\text { valoração }\end{array}$ & $\begin{array}{l}\text { - Por ser uma equipe } \\
\text { multidisciplinar, } \\
\text { possui técnicas de } \\
\text { valoração eficientes }\end{array}$ \\
\hline Estrutura interna & $\begin{array}{l}\text {-Atende a Lei da } \\
\text { Inovação } \\
\text {-Espaço físico e } \\
\text { equipe ideais }\end{array}$ & $\begin{array}{l}\text {-Atende a Lei da } \\
\text { Inovação } \\
\text { Equipe e espaço } \\
\text { físicos ideais }\end{array}$ & $\begin{array}{l}\text {-Atende a Lei da } \\
\text { Inovação } \\
\text {-Dividida em } \\
\text { setores } \\
\text { interdependentes }\end{array}$ & $\begin{array}{l}\text {-Atende a Lei da } \\
\text { Inovação } \\
\text {-Equipe } \\
\text { multidisciplinar } \\
\text { integrada }\end{array}$ \\
\hline
\end{tabular}

Nota. Elaborado pelos autores a partir de dados da pesquisa, 2014.

Diante do quadro acima pode-se concluir que as universidades pesquisadas atendem às exigências da Lei da Inovação de 2004. Os Núcleos de Inovação Tecnológica das universidades são os gestores da tecnologia e da inovação desenvolvidos dentro das instituições.

\section{CONCLUSÕES}

A fim de aumentar a competitividade é necessário que as empresas busquem alternativas inovativas a fim de se destacar no mercado. Diante disso torna-se necessário estudar soluções para que as empresas obtenham tecnologia de forma eficiente. Uma dessas formas é o processo de transferência de conhecimentos que são desenvolvidos em instituições de pesquisa. O objetivo desse trabalho então foi apresentar uma análise crítica sobre os processos de transferência de tecnologia por meio do processo de licenciamento de patentes das principais Universidades brasileiras, evidenciando como as universidades se organizam dentro da sua gestão de tecnologia a fim de a transferir para sociedade em geral. É sabido que o licenciamento não é a única forma de transferência de tecnologia existente, porém o foco do trabalho buscou restringir a essa modalidade que segundo o INPI (2012), é a maneira mais usada pelos institutos para a inovação tecnológica.

Para respaldar a pesquisa foi necessário o estudo sobre a interação entre a universidade e a sociedade, o processo de transferência de tecnologia e o gerenciamento de processos que permitiu elaborar fluxogramas a fim de ilustrar como essas celebrações são feitas. 
O objetivo do trabalho foi alcançado a medida que os ferramentais metodológicos foram utilizados como os questionários semiestruturados, a ferramenta $5 \mathrm{~W} 1 \mathrm{H}$ em cada etapa do processo e os fluxogramas.

Diante disso conclui-se que as universidades pesquisadas atendem à Lei da Inovação de 2004 ao compor os núcleos de inovação tecnológica a fim de gerir a tecnologia e promover a transferência para a sociedade em geral. As informações são na maioria das instituições de fácil acesso tanto para o pesquisador como para empresas que desejam inovar. Quando uma empresa encontra uma tecnologia e deseja se apropriar dela, as agências têm todos os ferramentais para efetuar essa transferência, desde adequação de editais e todos os trâmites jurídicos, como o valor que a empresa deverá pagar para se apropriar dessa nova tecnologia.

Cada universidade possui peculiaridades devido ao ambiente institucional presente e as legislações. Algumas agências possuem autonomia em seus processos como no caso da Unicamp, em outras o processo está fortemente vinculado a reitoria da universidade como no caso da UFMG.

A grande diferença que foi encontrada entre as universidades pesquisadas é o total de produção científica e o total de depósitos de patentes registrados. Como a USP possui um volume maior de produção científica por ano, isso acarreta num maior número de patentes depositadas, portanto a agência é maior e mais estruturada. Ou seja, todas as agências estão de acordo com a realidade encontrada na universidade e as boas práticas na gestão da tecnologia são melhoradas em conjunto com a produção científica e tecnológica da universidade em que a agência está inserida.

\section{REFERÊNCIAS}

Araújo, E. F., Barbosa, C. M., Queiroga, E. S., \& Alves, F. F. (2010). Propriedade intelectual: proteção e gestão estratégica do conhecimento. R. Brás. de Zootec., 39, 1-10.

Barbará, S. (2008). Gestão por Processos - Fundamentos, Técnicas e Modelos de Implementação. Rio de Janeiro: Qualitymark.

Cohan, P. S. (1998). Liderança tecnológica: como as empresas de alta tecnologia inovam para obter sucesso. São Paulo: Futura.

Cooper, D. R., \& Schindler, P. S. (2003). Métodos de pesquisa em administração (7ª Ed.). Porto Alegre: Bookman.

Creswell, J. W. (2007). Projeto de Pesquisa: métodos qualitativo, quantitativo e misto (2a Ed). Porto Alegre: Artmed.

Davenport, T. H. (1998). Reengenharia de processos. Rio de Janeiro: Campus. 
Dudziak, E. A. (2007). Lei de Inovação e pesquisa acadêmica: o caso PEA (Tese de doutorado). Escola Politécnica da Universidade de São Paulo.

Etzkowitz, H. (2004). The evolution of the entrepreneurial university. International Journal Technology and Globalization, 1(1), 64-77.

Evans, P. (2004). Autonomia e Parceria: Estados e transformação industrial. Rio de Janeiro: UFRJ.

Freire, I. M. (1991). Barreiras na comunicação da informação tecnológica. Ciência da Informação 20(1), 51-54.

Garnica, L. A., Vicentim, F. L. P., Entorno, D. M. D., \& Massambani, O. (2008). Incorporando Boas Práticas Internacionais à Gestão da Inovação da Universidade de São Paulo-USP. Trabalho apresentado no XXV Simpósio de Gestão e Inovação Tecnológica, Brasília.

Garnica, L. A. (2007). Transferência de tecnologia e gestão da propriedade intelectual em universidades públicas no Estado de São Paulo (Dissertação de Mestrado). Universidade Federal de São Carlos, São Carlos-SP.

Gonçalves, J. E. L. (2000). As empresas são grandes coleções de processos. Revista de Administração de Empresas/EAESP/FGV, 40 (1).

Hamer, M., \& Champy, J. (1994). Reengineering the Corporation. New York: HarperBusiness. Retirado de http://www.wipo.int/ip-development/en.

Humpfrey, W. A Process or a Plan? Retirado de http://www.sei.cmu.edu/publications/articals/wattshumpfrey/changing-word-sw.html.

Kim, L. (2005). Da imitação à inovação: a dinâmica do aprendizado tecnológico da Coréia. Campinas-SP: UNICAMP.

Maués, L. M. F. (1996). Metodologia de Organização interna e melhoria do processo produtivo em centrais de montagem de componentes: um estudo de caso (Dissertação de mestrado). Universidade Federal de Santa Catarina - UFSC, Florianópolis.

Lei 10.973. (2004). Dispõe sobre incentivos à inovação e à pesquisa científica e tecnológica no ambiente produtivo e dá outras providências. Brasília - Brasil. Retirado de http://www.mct.gov.br/index.php/content/view/8477.html.

Moreira, B. et al. (2008). As oportunidades e desafios do Open Innovation no Brasil. Instituto Inovação.

Retirado

de http://www.institutoinovacao.com.br/internas/artigo/idioma/1/154/Oportunidades+e+Desafios+do+ Open+Innovation+no+Brasil. .

Mota, T. L. N. G. (2011). Interação universidade-empresa na sociedade do conhecimento: reflexões e realidade. IBICT. Retirado de http://www.ibict.br/cionline/280199/28019911.pdf.

PITCE (2011). Política Industrial, tecnológica e de Comércio Exterior, retirado de http://www.abdi.com.br/?q=node/126.

Rummler, G. A., \& Brache A. P. (1994). Melhores desempenhos das empresas. São Paulo: Makron Books.

Revista de Administração e Inovação, São Paulo, v. 12, n.3, p. 28-55, jul./set. 2015. 
Santos, M. E. R., Toledo, P. T. M., Lotufo, R. de A. [Orgs.]. (2009). Transferência de Tecnologia: Estratégias para a estruturação e gestão de Núcleos de Inovação Tecnológica. Campinas, SP: Komedi.

Serra, C. S. (2010). Proposta de Institucionalização do processo de gestão da inovação tecnológica na Universidade Federal de Mato Grosso do Sul: da criação ao direito de proteção intelectual (Dissertação de Mestrado). Universidade Federal de Mato Grosso do Sul, Campo Grande-MS.

UNB. (2011). Universidade de Brasília. Centro de Apoio ao Desenvolvimento Tecnológico. Retirado de http://www.cdt.unb.br/view/sobreCDT.php.

Unicamp. (2010). Universidade Estadual de Campinas. Agência de Inovação Inova Unicamp. Retirado de http://www.inova.unicamp.br/paginas/visualiza_conteudo.php?conteudo=1.

Unicamp. (2011). Universidade Estadual de Campinas. Agência de Inovação Inova Unicamp. Retirado de http://www.inova.unicamp.br/paginas/visualiza_conteudo.php?conteudo=1.

USP. (2011). Universidade de São Paulo. Agência USP de Inovação. Retirado de http://www.inovacao.usp.br/institucional/historico.php.

USP. (2013). Universidade de São Paulo. Anuário USP. Retirado de https://uspdigital.usp.br/anuario/.

Villares, F. (2007). Propriedade Intelectual: tensões entre o capital e a sociedade. São Paulo: Ed. Paz e Terra.

Zeleza, P. T. (2005). Sociedade de conhecimento versus economia do conhecimento: conhecimento, poder e política. Brasília: UNESCO, SESI. 


\title{
ANALYSIS OF PATENT LICENSE MANAGEMENT: INSTITUTIONS STUDY MULTICASES FEDERAL HIGHER EDUCATION
}

\begin{abstract}
The quest for innovation by businesses becomes necessary due to increased competition and universities has an important role when partners in generation of technology and innovation. Therefore the purpose of this study was to discuss how the top universities in Brazil are the management of patents generated in order to transfer the company. The analyzes were based on research done in universities in the sample and to illustrate this management tools were used $5 \mathrm{~W} 1 \mathrm{H}$ and flowcharts for better organization and presentation of data. The analysis concluded that universities surveyed meet the requirement of the Law of Innovation which require that they dispose a core of technological innovation in order to manage the technology produced. But each university has peculiarities about their processes due to the institutional environment formed and internal regulations which results in bureaucracy for companies to have access to technology.
\end{abstract}

Key words: Innovation Management; Technology Transfer; Patents.

Data do recebimento do artigo: 10/03/2014

Data do aceite de publicação: 15/01/2015

Revista de Administração e Inovação, São Paulo, v. 12, n.3, p. 28-55, jul./set. 2015. 